\title{
Abnormal intestinal permeability to sugars in diabetes mellitus
}

\author{
A. D. Mooradian ${ }^{1,3}$, J. E. Morley ${ }^{1,3}$, A.S. Levine ${ }^{1,3}$, W. F. Prigge ${ }^{2,3}$ and R. L. Gebhard ${ }^{2,3}$ \\ ${ }^{1}$ Neuroendocrine Research Laboratory and ${ }^{2}$ Division of Gastroenterology, Minneapolis VA Medical Center, Minneapolis, Minnesota and \\ ${ }^{3}$ Department of Medicine, University of Minnesota, Minneapolis, Minnesota, USA
}

\begin{abstract}
Summary. A test of intestinal mucosal function which utilizes the differential permeability of L-rhamnose and lactulose has been reported to be helpful in the diagnosis of gluten-sensitive enteropathy. We have applied this test to 48 male subjects with diabetes mellitus to evaluate its usefulness as a screening test in diabetic patients and to further study sugar absorption in these individuals. Total urinary lactulose excretion in the 13 healthy control subjects was $54.5 \pm 8.5 \mathrm{mg} / 5 \mathrm{~h}$, while excretion by diabetic patients was increased at $116.1 \pm 15.7 \mathrm{mg} / 5 \mathrm{~h}$ $(p<0.01)$. Similarly, total L-rhamnose excretion by diabetic patients was significantly higher $(139.7 \pm 14.3 \mathrm{mg} / 5 \mathrm{~h}$ vs $84.3 \pm 18.4 \mathrm{mg} / 5 \mathrm{~h}, p<0.05$ ). The ratio of percent urinary excretion for lactulose/L-rhamnose ( $\mathrm{L} / \mathrm{R}$ ratio) for diabetic
\end{abstract}

patients $(0.197 \pm 0.024)$ was not different from the control subjects $(0.151 \pm 0.2)$. Nine out of 48 diabetic patients studied had lactulose/L-rhamnose ratios higher than the mean plus two standard deviations of the control group, which might lead to the diagnosis of small bowel mucosal disease. Although we may have been detecting subclinical mucosal disease or gluten sensitive enteropathy in a subgroup, it appears that this test of intestinal mucosal function should be interpreted with caution in diabetic patients.

Key words: Diabetes mellitus, L-rhamnose, lactulose, malabsorption.
Diabetes mellitus has been reported to have a number of adverse effects on small intestinal function. Diarrhea is quite common in diabetic patients and is often attributed to autonomic neuropathy with impaired motor activity, although evidence for a pathogenic relationship is tenuous $[1,2]$. A few diabetic patients appear to have bacterial overgrowth resulting in malabsorption [3]. Maldigestion may occur when pancreatic exocrine insufficiency accompanies endocrine insufficiency or when increased fecal loss of bile acids occurs [4]. In addition, gluten-sensitive enteropathy appears to be more common in diabetic patients and may cause severe malabsorption $[5,6]$. Finally, there is evidence for increased transport of sugars by intestinal mucosa of diabetic patients [7-9]. Reports are mixed [10], but excessive absorption of glucose, galactose and 3-0 methylglucose have been reported.

Recently, tests of mucosal function which utilize the differential permeability of a monosaccharide and a disaccharide have been reported to be helpful in the diagnosis of patients with gluten-sensitive enteropathy [11-15]. It has been observed that ingestion of two differently sized sugars which are not actively transported nor hydrolyzed in the small intestine, such as the monosaccharide rhamnose and the disaccharide lactulose, show different passive permeability through the intestinal mucosa of patients with the mucosal injury of coeliac sprue compared to normal subjects. Thus, permeability of the small molecule decreases in sprue. The test, then, consists of administering an oral dose of the two sugars and measuring uptake by urinary excretion. A ratio developed from the formula [percent of admin- istered lactulose excreted/percent of administered Lrhamnose excreted] is increased in patients with glutensensitive enteropathy. We have applied this test to a large group of diabetic patients, using a sugar solution identical in its composition to the test solution used in a previous study of patients with villous atrophy [14], in order to evaluate its usefulness as a screening test in diabetic patients and to further study sugar absorption in these individuals.

\section{Subjects and methods}

Forty-eight male subjects with diabetes mellitus were studied after giving informed consent. The mean age of the subjects was $52.4 \pm$ 1.8 years (range 26-74). All except 14 were on insulin therapy. The mean fasting plasma glucose was $200 \pm 14.4 \mathrm{mg} / \mathrm{dl}$ (range $68-456 \mathrm{mg}$ / $\mathrm{dl}$ ) and the mean glycosylated haemoglobin was $10.3 \pm 0.33 \%$ (range $7.0-17.9 \%$ ). Thirteen of the diabetic patients had clinically significant renal disease, indicated by creatinine greater than 1.3 or proteinuria greater than a trace. None of the patients had a serum creatinine greater than 2.0. Results were compared to those of 13 male controls ranging in age from 27 to 62 years. All controls had normal fasting plasma glucose and glycosylated haemoglobin levels.

Following an overnight fast, the subjects ingested an oral sugar solution containing $20 \mathrm{~g}$ lactose, $20 \mathrm{~g}$ sucrose, $1 \mathrm{~g}$ L-rhamnose and $5 \mathrm{~g}$ lactulose added as $7.5 \mathrm{cc}$ Cephulac (Merrell Dow, Cincinnati, OH, USA) in a volume of $110 \mathrm{cc}$ (the Cephulac solution also provided less than $1.1 \mathrm{~g}$ galactose, less than $0.6 \mathrm{~g}$ lactose and less than $0.6 \mathrm{~g}$ other sugars). The solution was hyperosmolar $(1505 \mathrm{mOsm} / \mathrm{l})$ to enhance oligosaccharide permeability [11,12]. Subjects ingested the undiluted solution within a period of $3 \mathrm{~min}$ and followed this with an equal volume of water. Patients remained fasting for two additional $h$ and then took water ad libidum to facilitate adequate urine output. A 5-h collection of urine was obtained. The volume was recorded and a sample preserved with merthiolate (Thiomersal $1 \mathrm{mg} / 10 \mathrm{ml}$ urine) was stored 


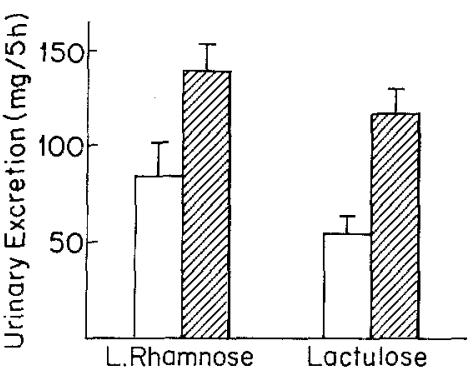

Fig. 1. Urinary excretion of L-rhamnose and lactulose in diabetic patients (7) $n=46)$ and control subjects $(\square n=13)(p<0.05$ for L-rhamnose and $p<0.01$ for lactulose excretion)

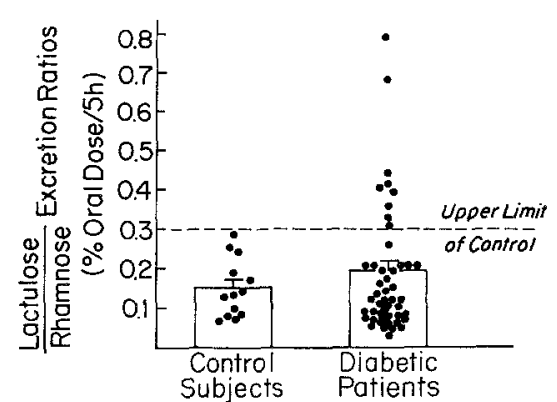

Fig. 2. Ratios of urinary lactulose to L-rhamnose excretion (expressed as a percentage of the oral dose) in diabetic patients $(n=48)$ and control subjects $(n=13)$

at $-20^{\circ} \mathrm{C}$ for analysis. The ingestion of the test solution of sugars did not result in any symptoms suggestive of lactose intolerance in the group of subjects studied.

\section{Chemical procedures}

Lactulose and rhamnose were measured in urine by a modification of the method of Laker [16]. Briefly, $0.3 \mathrm{ml}$ of a solution containing $1 \mathrm{mg} /$ $\mathrm{ml}$ turanose and $\alpha$-methylglucose as internal standards was added to $2.7 \mathrm{ml}$ urine. Desalting was accomplished by adding the mixed bed resin Amberlite MB-3 in the $\mathrm{H}^{+}$acetate form to $50 \%$ height of resin plus urine [17]. The tubes were mixed for $5 \mathrm{~min}$ on a rotary mixer and then centrifuged. One $\mathrm{ml}$ aliquot was pipetted into $13 \times 100 \mathrm{~mm}$ ground glass stoppered tubes and evaporated to dryness at $60^{\circ} \mathrm{C}$ under a $\mathrm{N}_{2}$ stream. Trimethylsilyl derivatives were prepared with $0.5 \mathrm{ml}$ anhydrous pyridine-bistrimethylsilylacetamide-trimethylchlorosilane $5: 1: 1$ in stoppered tubes at $60^{\circ} \mathrm{C}$ for $30 \mathrm{~min}$.

One $\mu$ l samples ran at $150^{\circ} \mathrm{C}$ on the Hewlett-Packard 5830A GLC (Hewlett-Packard, Palo Alto, CA, USA) equipped with a 6-ft glass column ( 0.25 in OD, 2 mm ID) packed with $3 \%$ SP-2250 on $100 / 120$ Supelcoport yielded a constant ratio of two peaks for rhamnose at 2.5 and $3.2 \mathrm{~min}$ and an $\alpha$-methylglucose peak at $13.30 \mathrm{~min}$. It was noted early that urine from diabetic patients contained substances that interfered with the $\alpha$-methylglucose peak and the second rhamnose peak. Measurement of rhamnose was therefore accomplished by direct calibration from the integration counts of known rhamnose concentrations using the first peak from $1-\mu$ injections.

Lactulose was measured using a $1-\mu l$ injection at $210^{\circ} \mathrm{C}$ with turanose as the internal standard. Retention times for lactulose and turanose were 10.64 and $13.75 \mathrm{~min}$ respectively. No interfering substances were present. Specifically, the disaccharide lactose did not interfere with this peak since its retention time on this column was longer in our experience and that of others [16]. Total lactulose and rhamnose excretion for $5 \mathrm{~h}$ was calculated from the concentration and urine volume.

\section{Statistical analysis}

Results are expressed as mean \pm SEM. The two-tailed Student's t-test for unpaired values was used. All results were logarithmically transformed before being analyzed because of the heteroscedasticity of the distribution of values in the control subjects. In addition, the MannWhitney test for non-parametric data was used to confirm the statistical significance of the differences observed between diabetic patients and control subjects.

\section{Results}

Lactulose excretion in the 13 healthy control subjects was $54.5 \pm 8.5 \mathrm{mg} / 5 \mathrm{~h}$ (mean $\pm \mathrm{SEM}$ ) with a range of $23-112.5 \mathrm{mg} / 5 \mathrm{~h}$. Excretion by diabetic patients was increased at $116.1 \pm 15.7 \mathrm{mg} / 5 \mathrm{~h}$ (range $=13.9-568.0 \mathrm{mg}$ / 5 h) $(p<0.01)$ (Fig. 1). Seventeen diabetic patients excreted an amount of lactulose which was greater than 2 standard deviations above the mean of normal excretion $(115.9 \mathrm{mg} / 5 \mathrm{~h})$.

Urinary excretion of L-rhamnose by normal subjects was $84.3 \pm 18.4 \mathrm{mg} / 5 \mathrm{~h}$ (range $31.5-290 \mathrm{mg} / 5 \mathrm{~h}$ ), while excretion by diabetic patients was $139.7 \pm$ $14.3 \mathrm{mg} / 5 \mathrm{~h} \quad$ (range $=31.1-601.7 \mathrm{mg} / 5 \mathrm{~h}) \quad(p<0.05)$. Seven diabetic patients excreted an amount of L-rhamnose which was greater than 2 standard deviations above normal $(216.7 \mathrm{mg} / 5 \mathrm{~h}$ ) (Fig. 1 ). Thus, $15 \%$ of diabetic patients displayed hyperexcretion and presumed hyperabsorption of rhamnose, while $36 \%$ showed hyperabsorption of lactulose. Six patients showed excessive excretion of both sugars ( $86 \%$ of patients with high rhamnose also had high lactulose), indicating an association between hyperexcretion of both sugars in diabetic subjects. The $5 \mathrm{~h}$ urinary volume of diabetic patients was not significantly different from that of the control subjects $(449 \pm 38 \mathrm{ml}$ vs. $321 \pm 65 \mathrm{ml}$ respective$1 y)$. When the diabetic patients with proteinuria were compared to those without any evidence of renal disease, there was no difference in lactulose excretion $(115.1 \pm 19.9$ vs $119.5 \pm 18.5 \mathrm{mg} / 5 \mathrm{~h}$ respectively) nor in L-rhamnose excretion $(140.7 \pm 18$ vs $136 \pm 18 \mathrm{mg} / 5 \mathrm{~h})$.

The urinary lactulose/L-rhamnose $(\mathrm{L} / \mathrm{R})$ ratio was calculated from $5 \mathrm{~h}$ excretions expressed as a percentage of the oral dose for the individual test sugars (Fig. 2). For the healthy controls, percentage lactulose/ L-rhamnose excretion ratios $(\mathrm{L} / \mathrm{R})$ were $0.151 \pm 0.20$ (range $=0.069-0.286$ ), while the ratio for diabetic subjects was $0.197 \pm 0.024$ (range $=0.034-0.793$ ). The differences between the two groups was not statistically significant. However, nine out of 48 diabetic patients and none of the normal subjects studied had a L/R ratio higher than 0.297 (mean plus two standard deviations of the control group), which might be interpreted as suggesting a diagnosis of small bowel mucosal disease. None of these subjects had a history of chronic diarrhea, weight loss, or clinical evidence for malabsorption, and the serum carotene level and qualitative stool fat determination were normal in the six subjects avail- 
Table 1. Urinary excretion of L-rhamnose, lactulose and percent lactulose/percent L-rhamnose $(\mathrm{L} / \mathrm{R})$ ratio in different subgroups of diabetic patients: Type 1, Type 2, those on insulin therapy, those on oral hypoglycaemic agents and Type 2 diabetic patients on insulin

\begin{tabular}{|c|c|c|c|}
\hline \multirow[t]{2}{*}{ Diabetic patients } & \multirow{2}{*}{$\begin{array}{l}\text { Urinary excre- } \\
\text { tion of L-rham- } \\
\text { nose }(\mathrm{mg} / 5 \mathrm{~h})\end{array}$} & \multirow{2}{*}{$\begin{array}{l}\text { Urinary excretion } \\
\text { of lactulose } \\
(\mathrm{mg} / 5 \mathrm{~h})\end{array}$} & $\%$ Lactulose \\
\hline & & & $\%$ L-rhamnose \\
\hline $\begin{array}{l}\text { Type 1 } \\
\qquad(n=8)\end{array}$ & $199.6 \pm 64.2$ NS & $\begin{array}{r}207 \pm 62.4 \\
p<0.05\end{array}$ & $\begin{array}{c}0.293 \pm 0.07 \\
\text { NS }\end{array}$ \\
\hline $\begin{array}{l}\text { Type } 2^{\mathrm{a}} \\
(n=40) \\
\text { On insulin }\end{array}$ & $127 \pm 10.5$ & $96.9 \pm 12.2$ & $0.178 \pm 0.02$ \\
\hline $\begin{array}{l}(n=34) \\
\text { (Types } 1 \& 2)\end{array}$ & $\begin{array}{ll}152.9 \pm 19.1 & \\
& \text { NS }\end{array}$ & $\begin{aligned} 137.3 \pm 20.4 & \\
p & <0.01\end{aligned}$ & $\begin{array}{l}0.23 \pm 0.03 \\
p<0.01\end{array}$ \\
\hline $\begin{array}{l}\text { Oral hypoglycaemic } \\
\text { agents }(n=14)\end{array}$ & $\begin{array}{rr}109.4 \pm 14.7 & \\
& \text { NS }\end{array}$ & $\begin{aligned} 67.7 \pm 16.8 & \\
p & <0.05\end{aligned}$ & $\begin{array}{r}0.117 \pm 0.02 \\
p<0.05\end{array}$ \\
\hline $\begin{array}{l}\text { On insulin }{ }^{\mathrm{a}} \\
(n=26) \\
\text { (Type 2) }\end{array}$ & $137.4 \pm 14.1$ & $114 \pm 16.0$ & $0.21 \pm 0.04$ \\
\hline
\end{tabular}

a 5 -h urinary excretion of $\mathrm{L}$-rhamnose and lactulose for 2 patients was not calculated because volume of urine output during the $5 \mathrm{~h}$ collection was not recorded. However, the ratio of $\%$ lactulose $/ \% \mathrm{~L}$-rhamnose could be measured

able for further testing. Six of the nine (67\%) did have microvascular and neuropathic complications of the disease compared to only $31 \%$ of those diabetic patients with normal $\mathrm{L} / \mathrm{R}$ ratios $(p<0.05)$. There was no correlation between the body weight of the diabetic patients and the amount of lactulose or L-rhamnose excreted nor their ratio. Similarly, there was no correlation with age or with fasting plasma glucose or glycosylated haemoglobin levels.

Table 1 shows that subjects with Type 1 (insulindependent) diabetes mellitus had significantly higher urinary lactulose excretion when compared to Type 2 (non-insulin-dependent) diabetic subjects (207士 $62 \mathrm{mg} / 5 \mathrm{~h}$ vs $96.9 \pm 12 \mathrm{mg} / 5 \mathrm{~h}, p<0.05$ ). The urinary excretion of L-rhamnose and the $\mathrm{L} / \mathrm{R}$ ratio were modestly but not significantly higher in Type 1 diabetic subjects. When diabetic subjects on insulin therapy were compared to those on oral hypoglycaemic agents, the urinary excretion of lactulose as well as the $\mathrm{L} / \mathrm{R}$ ratio was significantly higher $(p<0.01)$ in those on insulin therapy $(137.3 \pm 20 \mathrm{mg} / 5 \mathrm{~h}$ vs $67.7 \pm 16.8 \mathrm{mg} / 5 \mathrm{~h}$ for lactulose and $0.23 \pm 0.03$ vs $0.117 \pm 0.02$ for $\mathrm{L} / \mathrm{R}$ ratio). Similarly the urinary excretion of L-rhamnose was modestly higher in subjects on insulin therapy $(152.9 \pm$ $19.1 \mathrm{mg} / 5 \mathrm{~h}$ vs $109.4 \pm 14.7 \mathrm{mg} / 5 \mathrm{~h}$ ). The difference did not reach statistical significance.

To evaluate the effect of insulin therapy, Type 2 diabetic subjects on insulin were compared to those on oral hypoglycaemic agents. Those who were on insulin had significantly higher $(p<0.05)$ urinary excretion of lactulose and higher $\mathrm{L} / \mathrm{R}$ ratios $(p<0.05)$ as compared to those on oral agents $(114 \pm 16 \mathrm{mg} / 5 \mathrm{~h}$ vs $67.7 \pm$ $16.8 \mathrm{mg} / 5 \mathrm{~h}$ for lactulose and $0.21 \pm 0.04$ vs $0.117 \pm 0.02$ for $L / R$ ratio). There was no statistically significant difference in L-rhamnose excretion between the two groups (137.4 $\pm 14.1 \mathrm{mg} / 5 \mathrm{~h}$ vs $109.4 \pm 14.7 \mathrm{mg} / 5 \mathrm{~h}$ ).

\section{Discussion}

Diabetic subjects as a group had higher $5 \mathrm{~h}$ urinary excretion of both lactulose and L-rhamnose as compared to healthy control subjects, despite the fact that diabetic subjects might have had delayed gastric emptying or atonic bladders secondary to autonomic neuropathy. This suggests that there may have been increased passive intestinal sugar transport in some patients with diabetes mellitus, in line with the previously reported increase in intestinal sugar transport observed in animal models of diabetes $[8,18,19-21]$. Bacterial overgrowth often present in diabetic patients cannot account for the observed differences, since it should have lead to decreased lactulose and L-rhamnose-excretion in diabetic patients. Similarly, it is unlikely that an increased renal glomerular permeability could account for our findings, since there was absolutely no difference in urinary excretion of both lactulose and L-rhamnose when diabetic patients with renal disease were compared to those with normal renal function. In addition, the 5-h urinary volume of diabetic patients was not substantially different from that of the control subjects, suggesting that the increased urinary flow rates did not contribute significantly to the increased urinary lactulose and Lrhamnose excretion. The lack of correlation between the fasting plasma glucose levels on the day of testing, a major determinant of glycosuria and osmotic diuresis, and the urinary excretion of lactulose or L-rhamnose supports this contention. However, it is possible that subtle alterations in glomerular permeability may have increased the urinary excretion of these test sugars in diabetic patients. The effect of diabetes on active or passive intestinal glucose uptake in human subjects is controversial. Vinnik et al. [9] used intestinal perfusion to report greater removal of glucose from the lumen of diabetic patients compared to normal subjects. Subsequently, a clinical study which used much lower osmolarity of perfused lumenal sugars did not detect increased intestinal glucose transport [10]. The difference in results of these two reports may relate to the osmolarity of sugar solutions used, since osmolarity appears to have an effect on mucosal permeability $[11,12]$, although neither study used particularly hyperosmolar solutions. The reason for increased intestinal sugar transport in diabetes mellitus is not clear. There is some evidence to suggest that increased carbohydrate intake or hyperglycaemia per se may stimulate active intestinal glucose absorption $[8,22,23]$, possibly by inducing carriers for the transport, expressed kinetically as increased maximal transport rate $\left(\mathrm{V}_{\max }\right)$ of glucose [22-24]. In addition, several studies have reported increased intestinal mass in animal models of diabetes, which in itself could contribute to the increased sugar transport $[24,25]$. In the present study there was no correlation between sugar transport and fasting plasma glucose or glycosylated haemoglobin nor with weight of the diabetic subjects. 
The increased ratio of urinary excretion of lactulose to L-rhamnose $(\mathrm{L} / \mathrm{R})$ has been suggested to be a marker of abnormal intestinal permeability [14]. In the present study the diabetic subjects as a group had a $\mathrm{L} / \mathrm{R}$ ratio of $0.197 \pm 0.024$, which is modestly but not significantly higher than that found in control subjects $(0.151 \pm$ 0.02 ). However, 9 out of 48 diabetic patients tested $(19 \%)$ had $\mathrm{L} / \mathrm{R}$ ratios above the upper limit of normal (mean plus two standard deviations for the control subjects), indicating that a significant proportion of the diabetic population might be interpreted as having abnormal intestinal mucosal permeability. The diabetic patients with high $L / R$ ratio did not differ from the rest of the diabetic subjects in gastrointestinal or nutritional symptoms, age, duration of diabetes, fasting blood glucose or glycosylated haemoglobin levels. However, 6 out of those $9(67 \%)$ had diabetic neuropathy and angiopathy as compared to $31 \%$ of the rest of the diabetic subjects. The significance of this observations is not clear at present. To our knowledge, there are no studies correlating chronic diabetic complications with intestinal absorptive abnormalities. It is noteworthy that the diabetic subjects who were on insulin therapy had higher urinary excretion of lactulose as well as higher $L / R$ ratios when compared to those on oral hypoglycaemic agents. A similar effect of insulin therapy was apparent within the group of Type 2 diabetic subjects (Table 1 ), suggesting an important effect of insulin therapy per se rather than the type of diabetes. Although it has been shown that insulin administration acutely does not alter intestinal glucose absorption both in diabetic and normal subjects [9], the effect of chronic insulin therapy on intestinal absorptive functions is not known. On the other hand, galactose absorption in rabbits can be inhibited by exogenous insulin [26], suggesting that insulin may alter intestinal absorption of some sugars. Although the effect of insulin on lactulose and L-rhamnose is not known, it is possible that intestinal absorption of these sugars was inhibited in the control subjects by the endogenous insulin secreted in response to the ingestion of sucrose and lactose in the test solution. Further work is necessary to determine the effect of insulin on intestinal absorption of various sugars.

It appears that a test of intestinal mucosal function utilizing differential permeability (uptake or excretion) of sugars should be interpreted with caution in diabetic patients. Although we may have been detecting subtle, subclinical mucosal disease or gluten-sensitive enteropathy in some patients, it is more likely that the excessive mucosal uptake of some sugars by diabetic mucosa results in altered values.

\section{References}

1. Malins JM and Mayne N (1969) Diabetic diarrhea: a study of thirteen patients with jejunal biopsy. Diabetes 18: 858-866

2. Whalen GE, Soergel KH, Geenen JE (1969) Diabetic diarrhea: a clinical and pathophysiological study. Gastroenterology 56: 1021-1032

3. Goldstein F, Wirts CW, Kowlessar OD (1970) Diabetic diarrhea and steatorrhea. Microbiologic and clinical observations. Ann Int Med 72: 215-218

4. Molloy AM, Tomkin GH (1978) Altered bile in diabetic diarrhea. Br Med J 2: 1462-1463

5. Ellenberg M (1963) Diabetic enteropathy. Am J Gastroenterol 40: 269-275

6. Shanahan F (1982) Coeliac disease and diabetes mellitus: a study of 24 patients with HLA typing. Q J Med 51: 329-335

7. Olsen WA, Rosenberg IH (1970) Intestinal transport of sugars and amino acids in diabetic rats. J Clin Invest 49: 96-105

8. Csaky TZ, Fischer E (1981) Intestinal sugar transport in experimental diabetes. Diabetes 30:568-574

9. Vinnik IE, Kern F Jr, Sussman KE (1965) The effect of diabetes mellitus and insulin on glucose absorption by the small intestine in man. J Lab Clin Med 66: 131-136

10. Costrini NW, Ganeshappa P, Wu W, Whalen GE, Soergel KH (1977) Effect of insulin, glucose and controlled diabetes mellitus on human jejunal function. Am J Physiol 233: E181-E187

11. Menzies IS (1974) Absorption of intact oligosaccharide in health and disease. Biochem Soc Transac 2: 1042-1046

12. Wheeler PG, Menzies IS, Creamer B (1978) Effect of hyperosmolar stimuli and coeliac disease on the permeability of the human gastrointestinal tract. Clin Sci Mol Med 54: 495-501

13. Cobden I, Rothwell J and Axon ATR (1980) Intestinal permeability and screening tests for coeliac disease. Gut 21: 512 -518

14. Menzies IS, Laker MF, Pounder R, Bull J, Heyer S, Wheeler PG, Creamer B (1979) Abnormal intestinal permeability to sugars in villous atrophy. Lancet 2: 1107-1109

15. Editorial (1981) Sugaring the Crosby capsule. Lancet 1: 593-594

16. Laker MF (1979) Estimation of disaccharides in plasma and urine by gas liquid chromatography. J Chromatogr 163: 9-18

17. Menzies IS (1973) Quantitative estimation of sugars in blood and urine by paper chromatography using direct densitometry. J Chromatog 81: 109-127

18. Caspary WF (1973) Effect of insulin and experimental diabetes mellitus on the digestive-absorptive function of the small intestine. Digestion 9: 248-263

19. Crane RK (1961) An effect of alloxan diabetes on the active transport of sugars by rat small intestine in vitro. Biochem Biophys Res Commun 4: 436-440

20. Leese HJ, Mansford KRL (1971) The effect of insulin and insulin deficiency on the transport and metabolism of glucose by rat small intestine of genetically diabetic mice. J Physiol (Lond) 212: $819-838$

21. Ramaswamy K, Peterson MA, Flint PW, Whalen GE (1980) Transport of monosaccharides by the small intestine of genetically diabetic mice. Gastroenterology 70: 464-469

22. Kotler DP, Levine GM, Shiau Y (1980) Effects of nutrients, endogenous secretions, and fasting on an in vitro glucose uptake. Am J Physiol 238: G219-G227

23. Thomson ABR (1982) Influence of dietary modifications on uptake of cholesterol, glucose, fatty acids and alcohols in rabbit intestine. Am J Clin Nutr 35: 556-565

24. Thomson ABR (1981) Uptake of glucose into the intestine of diabetic rats. Effects of variations in the effective resistance of the unstirred water layer. Diabetes 30: 247-255

25. Miller DL, Hanson W, Schadl HP, Osborne JW (1977) Proliferation rate and transit time of mucosal cells in small intestine of the diabetic rat. Gastroenterology 73: 1326-1332

26. Beyreiss K, Muller F, Strack E (1964) Über die Resorption von Monosacchariden. I. Der Einfluß von Insulin auf die Resorption der Galaktose. Z Ges Exp Med 138: 277-288

Received: 3 September 1985

and in revised form: 23 January 1986

Dr. John E. Morley

GRECC

VA Medical Center

16111 Plummer Street

Sepulveda, CA 91343

USA 